\title{
A Study of the Development Mode of Internet Finance in China in the Context of Big Data
}

\author{
Tingting Dou ${ }^{1, *}$, Geng Liu $^{2}$ \\ ${ }^{1}$ School of Economics and Management of XI'an Mingde Institute of Technology,Xi'an,Shaanxi,China \\ ${ }^{2}$ China Aero Engine Power Co. Ltd , Xi'an,Shaanxi,China
}

\begin{abstract}
In recent years, with the continuous development of China's financial technology, the relationship between Internet finance and computing information technology such as big data is getting increasingly close. Based on the existing research results, following the research ideas of finding, analyzing and solving problems, this paper studied several main development modes of Internet finance in China in the context of big data, and pointed out the existing problems, so as to put forward policy suggestions to optimize China's Internet finance on the basis of analyzing the reasons.
\end{abstract}

\section{INTRODUCTION}

In recent years, with the exploitation and application of the big data technology, the Internet finance in China continues to grow rapidly. But the study found that the existing Internet financial model still exist deficiencies. This article combined with the actual situation, analysis the Internet finance in China in the context of big data, so as to put forward policy suggestions to optimize China's Internet finance.

\section{DEVELOPMENT STATUS OF INTERNET FINANCE IN CHINA IN THE CONTEXT OF BIG DATA}

\subsection{Development of Internet Finance in China in the Context of Big Data}

The first year of Internet finance in China is 2005, but most of the early financial products are based on the online window platform model of commercial banks and other traditional financial institutions. Until 2012, after many years of initial stage, China has entered the e-commerce stage. The application of information technology by financial institutions has gradually deepened from the technical level to the business level, and China has ushered in the real scale development of Internet finance. In this process, a series of innovative Internet financial modes emerged. For example, in 2007, the first group of P2P network lending platforms - Paipai Loan, Alibaba's Yu'E Bao, and Jingdong Finance appeared one after another. Since then, the innovative Internet financial modes have shown explosive growth. By the end of 2018, there were about 6,063 P2P online lending platforms in China, of which the number of platforms in regular operation was about 1185. According to the list of top 100 financial technology companies released by KPMG and financial technology investment companies in 2018, three are from China in the top 10, among which Ant Financial Services Group and Jingdong Finance rank first and second, respectively. By the end of 2018, the transaction scale of China's third-party mobile payment market had reached RMB 47.2 trillion, an increase of $7.78 \%$ on a month-onmonth basis. Alipay occupies $53.78 \%$ of the total thirdparty transaction market share, ranking first, followed by Tencent Financial Technology, thus forming a monopoly with the two in the dominant position [2]. In the meanwhile, the standardization of the third-party market has gradually improved, and it is in a state of rapid growth and orderly competition.

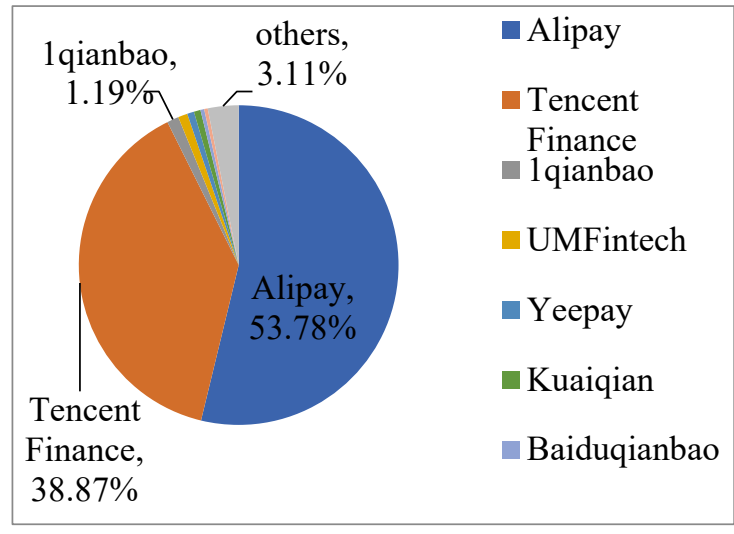

Fig.1. Transaction Share of China's Third-Party Mobile Payment Market in Q4 2018

*Corresponding author: 1106215324@qq.com 
Now China's Internet finance has the following modes: (1) P2P online lending mode, which is further divided into pure online mode (Paipai Loan, Renren Loan) and onlineoffline modes (Yilong Loan). (2) Third-party payment mode, which is further divided into independent thirdparty payment (Kuaiqian, Lakala, etc.) and third-party guarantee payment (Alipay, Tenpay, etc.). (3) Mode based on information financial institutions, such as CCB Shanrong Business, BCM Jiaobohui. (4) Mode based on Internet financial portal, such as Haodai.com, Software and Information Services Exchange as well as Rong 360. (5) Mode based on big data finance. It is further divided into platform mode (Ali Petty Loan) and supply chain finance (Jingdong Finance, Suning Finance). (6) Crowdfunding mode, such as Jingdong Crowdfunding, taomeng.com and Demo Hour [1].

Table 1. Supply chain market size of China from 2016 to 2020

\begin{tabular}{|l|l|}
\hline Year & $\begin{array}{l}\text { Size of market } \\
\text { (One trillion yuan) }\end{array}$ \\
\hline 2016 & 12.95 \\
\hline 2017 & 14.42 \\
\hline 2018 & 17.5 \\
\hline 2019 & 22.18 \\
\hline 2020 & 27.01 \\
\hline
\end{tabular}

\subsection{Main Development Modes of Internet Finance in China in the Context of Big Data}

\subsubsection{Mode of Supply Chain Finance -- Taking Jingdong Supply Chain Finance as an Example}

At present, the main supply chain finance mode of Jingdong is "Jingbaobei" and "Jing Petty Loan". Among them, "Jingbaobei" is the pool factoring financing scheme launched by Jingdong Finance, which is aimed at the suppliers of Jingdong. The suppliers transfer all their accounts receivable to the factoring agents, and the factoring agents determine the maximum amount according to the accounts receivable and provide the suppliers with financing services, so as to help them solve the problems of financing and slow lending. In contrast, "Jing Petty Loan" is targeted at the merchants on Jingdong's platform, providing loan for some businesses on the open platforms. The maximum amount is 5 million yuan, which is put into Jingdong Wallet and withdrawn to the corporate account. Through the above practices, Jingdong has formed a perfect closed loop between the service system of supply chain finance and its target customers.

In terms of businesses, from small loan, crowdfunding to consumer finance, from payment to bill, from wealth management to asset securitization, Jingdong has formed its own unique system; in terms of customers, it has formed a situation of having suppliers on top, customers on the bottom and relying on peers; in terms of big data technology application, Jingdong has established its own unique logistics distribution system by using big data technology as well as cost control and its own supply chain financial service system. It not only provides loans and financial services to upstream suppliers, but also provides credit sale and installment services to downstream consumers. Therefore, Jingdong has very high-quality upstream suppliers, downstream individual consumers and accurate big data information, and its financial business is developing well.

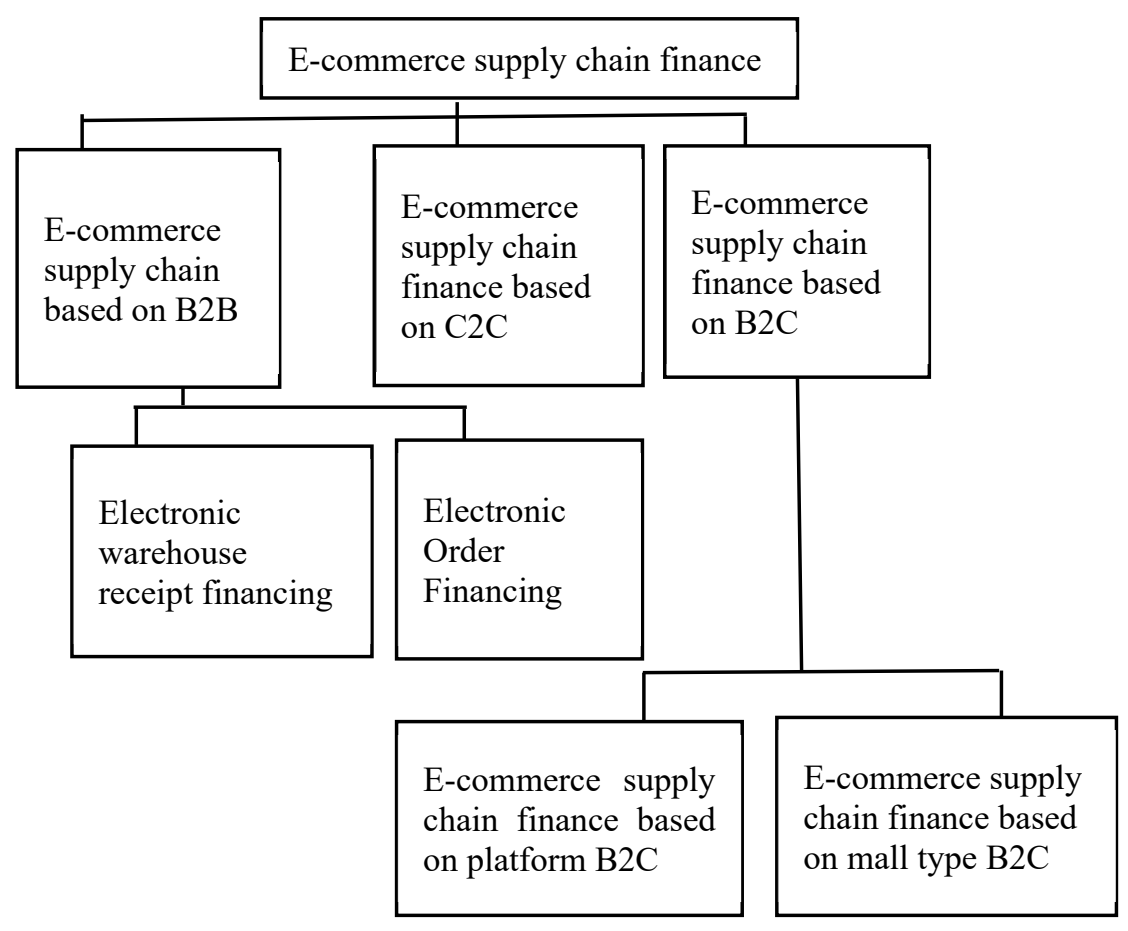

Fig.2. "E-commerce supply chain finance" mode classification 


\subsubsection{Financial Mode of Internet Platforms -- Taking Alibaba Petty Loans as an Example}

Alibaba has established e-commerce petty loans (Alibaba Petty Loans) since 2013. At present, its main products include TMALL order loans, credit loans and Juhuasuan loans. Its main lending mode is as follows. Alibaba uses cloud computing and video technology to build a quantitative model to determine the line of credit by processing the past transactions and credit data of the customers who have applied for the loan, and the borrower independently chooses the way of repayment. Due to the support of big data and quantitative technology, the loan amount of the borrower will vary with the transaction volume of the applicant [4]. Therefore, it is not too much to say that this is an innovative financial model tailored for borrowers.

In addition, relying on big data and other network technologies, this kind of loan mode realizes paperless operation, simplifies the loan process and saves the loan cost. Real-time data monitoring can help Alibaba avoid the default risk of customers, so as to achieve the sound development of Alibaba Petty Loans.

\subsubsection{The Third-party Payment of Internet Finance -- Taking Alipay as an Example}

Alipay, which sprang up in B2C business, has fundamentally changed the form of remittance in traditional network transactions [5]. It is a new payment revolution, and has also stimulated the growth of consumption in China. In terms of financing and credit, Alipay makes use of massive trading data to provide credit services for its target customers by constructing quantitative trading platform and analyzing the results of big data. It not only fully solves the problem of asymmetric information concerned by customers, but also effectively prevents risks through the closed-loop operation of funds. It provides a useful platform for the sound development of Internet finance in China.

\section{PROBLEMS IN THE DEVELOPMENT OF INTERNET FINANCE IN CHINA IN THE CONTEXT OF BIG DATA}

\subsection{Network Security}

In terms of technology, the application of big data is based on Internet information technology. However, the problems of network vulnerability and hacker intrusion have been major risks in Internet finance. For instance, small-sized enterprises are easy to be hacked by computer viruses, and the information can be heavily copied and tampered. How to protect data security and personal information privacy is an urgent problem to be solved. The network crime is characterized by short time and fast speed, which makes the work of risk prevention very difficult. Although China has been committed to the upgrading of network information security technology, the actual situation does not reach expectations, and the technology needs to be further improved.

The security system for Internet information security crime is insufficient. There is a lack of targeted punishment measures, and the existing punishment is not enough, mainly in the form of fines and other administrative penalties. These problems lead to frequent incidents of Internet financial information security.

The application of big data technology in Internet financial risk control in China has become the norm of various industries, but there are still deficiencies. For one thing, big data is mainly divided into transaction data and social data, but some data show low credibility, which is not enough to support the need of risk control. For another, the relevant theory of big data risk control lags behind and lacks guiding theory.

\subsection{Management}

With respect to customer management, the existing major e-commerce companies in China have not divided the target customer market into different levels, resulting in complicated businesses and large market span. In terms of marketing management, they still focus on traditional advertising marketing and lack active research on customers, so they are unable to form their own core competitiveness. As for supply chain financial management, due to the high transportation cost, logistics requires a large amount of working capital -- even higher than the value of the product itself, which leads to low capital turnover rate of enterprises, excessive occupation of working capital, reduced ability to resist risks, and huge capital chain gap of enterprises, thus restricting the businesses of Internet finance. With regard to information management, owing to the lack of comprehensive information sharing mechanism in China, there are still some problems in Internet finance such as information delay and excessive cost. In terms of personnel management, Internet companies generally have the problems of high staff mobility, high training cost and high dependence on talents, all of which increase the operating cost of Internet companies and hinder the effective development of Internet financial businesses.

\subsection{Risk Control}

The financial businesses on the Internet platforms are mainly credit financing, which highlights the credit risk in Internet finance. However, the existing credit risk assessment mechanism is still not perfect. It makes the credit risk more prominently exposed that the credit rating is only used to decide whether to grant a company a mortgage or even a loan limit.

The credit rating system in China is still not perfect, because the credit rating database is newly established and its operation is not standardized [6]. Furthermore, the information in the database is incomplete and its own system is not perfect. When the enterprises using platform finance use the current credit data to evaluate credit risks, there will be some errors, which makes the Internet financial industry face great challenges. In China, since 
some credit information may involve personal information security, trade secret and national security, they are easy to be illegally used by criminals for profits if not applied appropriately or without well-established system and mechanism.

Above all, due to a variety of credit ratings of Internet financial platforms in China, a lack of uniformity places risk control under great pressure. In China, some lending platforms take the certificates of houses and vehicles and income certificate as the basis of the borrower's credit rating. However, since the credit information provided is too scattered and it is also easy to fake, the reliability of actual verification between the borrower and the lender is significantly reduced, thus resulting in fraud and default.

\subsection{Financing Precipitation}

In online transactions, due to the unique transaction mechanism of the third-party payment platform, it is easy for the third-party platform to retain a large number of transaction funds. Taking Alipay, the largest third-party payment platform in China, as a case, its average daily capital settlement is over billions of yuan. Such a huge amount of funds will undoubtedly bring a series of risk problems.

According to the existing third-party transaction regulations in China, the funds from online shopping have to stay in the account of the third-party platform for at least 3-7 days. Due to the lack of supervision, some platforms may misappropriate the retained funds without authorization, resulting in a variety of moral hazards. In addition, if large-scale capital precipitation exceeds the amount of funds owned by the enterprise, it will lead to the collapse of the third-party platform. Therefore, it can be concluded that the risk of precipitation funds to the third-party payment platform mainly comes from the third-party payment platform itself.

Finally, the precipitation funds owned by the thirdparty payment platform may also bring about liquidity risk, and once this risk occurs, it will cause great losses to the seller. This is because when using the third-party platform in the transaction, the funds do not enter the seller's account, but stay in the third-party platform. Only after the buyer confirms the transaction, the third-party platform will transfer the funds to the seller, which makes the seller unable to obtain the financial support immediately, further leading to the seller unable to quickly carry out the capital turnover precipitation.

\section{MAIN FACTORS INFLUENCING THE DEVELOPMENT OF INTERNET FINANCE IN CHINA IN THE CONTEXT OF BIG DATA}

\subsection{Technical Factors}

In recent years, with the continuous development of science and technology, China's Internet financial enterprises' demand for data and their investment in it are also increasing, forming the trend of Internet financial big data. In China, because most internet financial enterprises are using big data technology, they can establish a service system that can achieve precision marketing by using this technology. For example, some internet financial enterprises use the data of customers' browsing traces on the Internet to lock the target service types of customers. Taking Alibaba as an example, they use big data technology to establish a user model. In the process of Taobao shopping, the users will use this model to make real-time recommendation, so as to achieve precision marketing and reduce costs.

However, although China's Internet financial enterprises have adopted big data technology, it is still not mature, and the technical level is not perfect. In particular, the personnel in the development of big data technology is very scarce. Therefore, China's big data technology is advancing slowly, and the innovation is insufficient. Moreover, there is still a certain gap compared with foreign developed countries in the aspect. It is safe to say that these technical deficiencies greatly curb the development of Internet finance in China.

\subsection{Legal Factors}

Due to the innovation of Internet finance mode, the accompanying risks also rise. In recent years, owing to the huge benefits of Internet finance, some Internet finance enterprises will only blindly imitate foreign Internet finance modes. However, these modes do not match the current situation of Internet financial market in China, and fail to satisfy the needs of customers, so they encounter their "Waterloo".

As the Internet itself has data security problems and the core of Internet finance comes from data, it can be said that the biggest threat to Internet finance is data security. In the era of big data, with the explosive growth of data, most of China's Internet financial enterprises have centralized data storage, because it is more convenient for enterprises to analyze and process data. However, due to the characteristics of the Internet, the data is vulnerable leakage, loss and damage.

\section{POLICY SUGGESTIONS ON STRENGTHENING THE DEVELOPMENT OF INTERNET FINANCE IN CHINA}

\subsection{Formulate Laws and Regulations}

At present, the relevant provisions and regulations of Internet finance development have been enacted in China, mainly aiming at the Internet financial mode in the narrow sense including P2P network loan, crowdfunding, thirdparty payment, etc. [3] Therefore, the Internet finance industry in China needs more perfect laws and regulations, and also puts forward higher requirements for the Internet supervision industry. In light of this, this paper suggests that China should establish a standardized and comprehensive regulatory system that is in line with the future development of China's Internet finance. This system should take into account the main body, the means 
and methods, so as to protect the development mode of Internet finance in China.

Meanwhile, since the relevant regulations of The Program of Action for Promoting the Development of Big Data has been enacted, we should give full play to the influence and role of big data technology in the process of the reform of Internet finance development mode, and further improve the efficiency, effectiveness and effect of "big data-driven", so that big data can really become a strong support for promoting financial system innovation.

\subsection{Establish a Big Data Sharing System}

To establish a big data sharing system, we should first actively promote the relevant laws and regulations on data resource sharing in China's Internet finance industry, so as to establish a more orderly and secure big data sharing system. By promoting the relevant laws and regulations of big data sharing, we can establish the corresponding sharing mechanism and make clear how to allocate different sharing subjects for different types of big data. On this basis, China's government regulatory departments should establish an evaluation index system for big data sharing, and then Internet financial institutions can decide how to share data, how often to share data, and the scope of sharing according to the evaluation of the system. Therefore, promoting the establishment of big data sharing system is conducive to the standardization of China's Internet financial industry and breaking the technical barriers caused by the "data island". At the same time, it is also conducive to strengthening the friendly cooperation between Internet financial institutions and benefiting the people.

\section{CONCLUSION}

Firstly, this paper based on the actual situation, in the context of the big data era, with Aliloan, JD Supply Chain Finance and Alipay as the research object, studies the main mode of Internet finance development in China under the background of big data.Secondly, it analyzes the problems in the main mode of China Internet finance development. Finally, this paper focus on relevant solutions and suggestions for the problems existing in China Internet finance, hoping that China Internet finance will have better development in the future.

\section{Acknowledgments}

Subject: This paper is one of the phased achievements of the special scientific research project of Shaanxi Provincial Department of Education, i.e., "Research on the Financing Mode of "Internet Finance + Agriculture Value Chain" in Shaanxi Province (No.: 19jk0867).

\section{REFERENCES:}

1. Ping Xie, Chuanwei Zou. Research on Internet Finance Mode [J]. Journal of Financial Research. 2012 (12).
2. Yonghong Du. Research on the Development Strategies of Internet Finance in the Era of Big Data [J]. Price: Theory \& Practice, 2015 (7).

3. Ying Liu, Mingxiong Luo. Big data Finance Promotes Cross-border Integration [J]. PKU Business Review, 2013 (11).

4. Xiao Feng, Yi Chen. Practice and Enlightenment of Big Data Credit Investigation Based on Internet Finance platform -- Taking "Ant Financial Service Group" of Alibaba as an Example [J]. China Market, 2015 (32).

5. Li Zou. Research on the Financing Mode of Small and Micro Enterprises based on Big Data -- Taking Alibaba Finance as an Example [J]. Communication of Finance and Accounting, 2016 (32).

6. Yonghong Du. Innovative Development Mode of Internet Finance in the Context of Big Data [J]. China Business and Market. 2015 (7). 